\title{
Role of olfactory and visual stimuli in the mating behaviour of male vine bud moths, Theresimima ampellophaga (Lepidoptera: Zygaenidae)
}

\author{
Teodora Borislavova TOSHOVA ${ }^{1}$, Mitko Angelov SUBCHEV ${ }^{1}$ and Miklós TÓTH² \\ ${ }^{1}$ Institute of Zoology, Bulgarian Academy of Sciences, Blvd. Tzar Osvoboditel 1, Sofia, 1000, Bulgaria; \\ e-mails: toshova@zoology.bas.bg; subchev@zoology.bas.bg \\ ${ }^{2}$ Plant Protection Institute, Hungarian Academy of Sciences, Pf 102, Budapest, H-1525, Hungary; e-mail: h2371tot@ella.hu
}

Key words. Lepidoptera, Zygaenidae, Theresimima ampellophaga, vine bud moth, sex pheromone, vision, mating behaviour

\begin{abstract}
The influence of olfactory and visual stimuli on the mating behaviour of Theresimima ampellophaga males was investigated in the field. A female model attached to a pheromone source significantly increased the number of males contacting and showing copulatory responses compared to their reaction to a pheromone stimulus alone. The pheromone stimulus was the primary factor releasing male copulatory behaviour, independent of the spatial arrangement of olfactory and visual cues. The role of the visual cues decreased with increasing distance between visual and olfactory cues. The reaction of males to pairs of models with different characteristics of conspecific females, in combination with a pheromone source placed $2 \mathrm{~cm}$ upwind from the center of the line between each pair of models, was compared. The size and shape of the female seemed not to be important, while the colour, posture, sex and species belongings significantly influenced the male's mating reaction.
\end{abstract}

\section{INTRODUCTION}

Olfactory chemical cues are primary stimuli for the location of mates, food and the selection of suitable oviposition sites by most lepidopteran species. Anemotaxis (wind-steering) plays a principal role in the long-range orientation of male moths to pheromone sources and the upwind flight tracks of these insects follow zigzagging patterns (Kennedy, 1983; Preiss \& Kramer, 1986; Cardé \& Mafra-Neto, 1996). Flight orientation behaviour of male moths to the chemical message depends on the structure and concentration of the pheromone plume (Kuenen \& Baker, 1982; Willis \& Baker, 1988, 1994; Charlton et al., 1993; Mafra-Neto \& Cardé, 1994; Vickers \& Baker, 1997; Schofield et al., 2003), visual field patterns (Baker \& Linn, 1984; Witzgall \& Priesner, 1984; Vickers \& Baker, 1994) and environmental factors such as wind speed (Mafra-Neto \& Cardé, 1998), temperature (Charlton et al., 1993), relative humidity (Royer \& McNeil, 1993) and light intensity (Cardé \& Knols, 2000). Close to the odour source, male moths often use visual cues in mate location (Farcas \& Shorey, 1974).

Investigations of the orientation behaviour of several moth species in the field and laboratory reveal that a combination of both physical and olfactory stimuli influences mate recognition (Shorey \& Gaston, 1970; Hidaka, 1972). The presence of a visual stimulus (dead female or mock female) significantly increases the catches of male Heliothis zea (Boddie) in pheromone traps (Gross et al., 1983). However, Charlton \& Cardé (1990a), and Willis at al. (1994) suggest that Lymantria dispar (L.) males use predominantly olfactory cues to locate the source, and the visual characteristics of the female or the substrate upon which she is resting are not important for male orientation. Similarly, Castrovillo \& Cardé (1980) found that a dead Laspeyresia pomonella (L.) female did not affect the time spent by conspecific males in orientation and finding of the experimental platform, independent of its location in relation to the pheromone source.

The family Zygaenidae includes over 1000 species worldwide with about 100 species grouped in five subfamilies - Zygaenidae, Procridinae, Chalcosiinae, Phaudinae and Callizygaeninae (Epstein at al., 1999). Sex pheromone communication in Zygaenidae is poorly investigated. Until now, sex pheromones have been identified for only two Procridinae species - Neoarctic species Harrisina brillians Barnes \& McDunnough (Myerson et al., 1982; Soderstrom et al., 1985) and Palaearctic Theresimima ampellophaga (Bayle-Barelle, 1808) (Subchev et al., 1998), in which the main sex pheromone compounds are (2S)-butyl-(7Z)-tetradecenoate and (2R)-butyl-(7Z)-tetradecenoate, respectively. In the field, both isomers, on their own, attracted several other Harrisina and Acoloithus (Procridinae) species. In addition to this, sex attractants, which are long chain (12, 14 or 16 carbon atoms) unbranched acetates or alcohols, are reported for several Zygaena species (Zygaeninae), (El-Sayed, 2005).

In the Zygaenidae, the interactions between chemical and visual cues in mate location behaviour are described only in Z. filipendulae (L.) (Zagatti \& Renou, 1984) and Z. trifolii (Esper) (Naumann, 1988, 1990; Prinz \& Naumann, 1988).

The aim of this study was to estimate the effect of olfactory and visual cues in mate recognition and mating behaviour of males of the vine-bud moth $T$. ampellophaga (Procridinae) in the field. 


\section{MATERIAL AND METHODS}

\section{Pheromone stimuli}

The synthetic sex pheromone of T. ampellophaga females, (2R)-butyl-(7Z)-tetradecenoate, used in these experiments was synthesized in the Institute of Organic Chemistry in Hamburg (Germany), as described by Subchev et al. (1998) and had an enantiomeric purity $>98 \%$. For establishing the effect of the dose of the pheromone source on male behaviour, three doses of the pheromone, $10 \mu \mathrm{g}, 50 \mu \mathrm{g}$ and $100 \mu \mathrm{g}$, dissolved in $10 \mu \mathrm{l}$ hexane, were applied to the cavity of grey rubber vial caps $(0.7$ $\mathrm{cm}$ diameter). In the rest of the experiments, pheromone stimuli using a $50 \mu \mathrm{g}$ dose of the synthetic sex pheromone were used. In these experiments, the same pheromone dispensers were used for 2-3 days and stored in a refrigerator at $-10^{\circ} \mathrm{C}$ before reuse.

\section{Female visual models}

We used three groups of female visual models:

(1) Dummy female. This was made of a pin wrapped with black threads for the head and abdomen and a piece of a feather dyed black for wings (Fig. 1). The dummy female was fixed to a piece of cork (2.1 cm diameter).

(2) Dead moths. To remove any chemical (pheromone) stimuli dead moths were rinsed several times in pure hexane. Each dead moth was fixed to a piece of cardboard $(2 \times 2 \mathrm{~cm})$.

(3) Cardboard models. 3-dimensional T. ampellophaga female models of different dimensions and colour patterns were cut from black cardboard. The basic (normal) model was black (1.2 cm long and $2.1 \mathrm{~cm}$ wing span) imitating a $T$. ampellophaga female in a calling posture, i.e. with abdomen curved dorsally and wings spread and directed downward to the substrate (see Fig. 1, Toshova \& Subchev, 2003). In addition to this, 2-dimensional models of different geometrical shapes were made of black cardboard.

\section{Experimental area}

Experiments were conducted in a private vineyard, untreated with insecticides, near Kecskemét in the South of Hungary on June 19-25, 2002, and an abandoned vineyard in Budakeszi in the North of Hungary on June 30 - July 1, 2002. Observations were conducted from 6.30 to 13.00 , which coincides with the main peak of female calling activity recorded in the laboratory (Toshova \& Subchev, 2003) and the main peak of male responsiveness to synthetic sex pheromone recorded in the field (Subchev et al., 2004). Air temperature was recorded every half hour throughout the experiments and was $27 \pm 2^{\circ} \mathrm{C}$.

The wind direction was determined using titanium tetrachloride smoke. Treatments were placed on a white plastic rectangle experimental platform $(40 \times 40 \mathrm{~cm})$ hung horizontally between two neighbouring vines at a height of about $1 \mathrm{~m}$ above the ground. To prevent contamination of the platform, each pheromone stimulus was fixed to a piece of cardboard $(2 \times 2 \mathrm{~cm})$. There were four series of experiments:

\section{Effect of pheromone dose}

The first series of experiments were conducted to compare the effect of different doses $(10 \mu \mathrm{g}, 50 \mu \mathrm{g}$ and $100 \mu \mathrm{g})$ of the synthetic sex pheromone on the response of males as the pheromone source was placed $5 \mathrm{~cm}$ upwind of a dummy female. For each combination (pheromone / dummy female), we recorded separately for $30 \mathrm{~min}$ : (1) the number of males orienting to the platform; (2) the number of males orienting and contacting to either the chemical or visual stimulus; and (3) the number of mating attempts toward each of the stimuli.

The male responses to the stimuli were weighted using Indices of male responses (IMR) (Richerson, 1977):

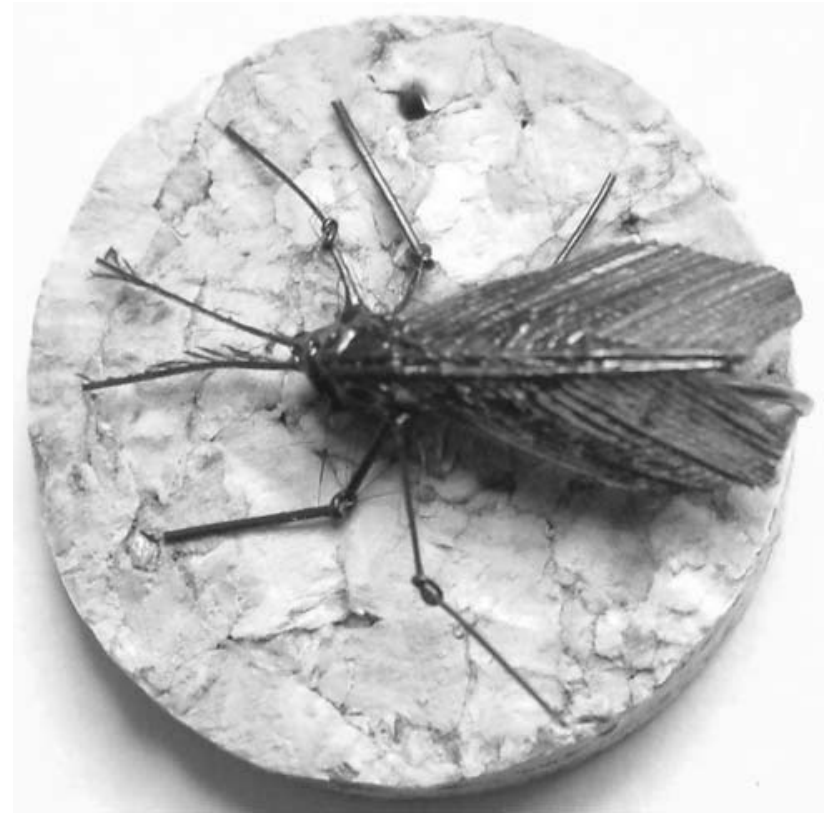

Fig. 1. Picture of a dummy female.

$\mathrm{IMR}_{\text {pheromone }}=0.15$ (number of males orienting to a test area in $30 \mathrm{~min}$ ) +0.35 (number of males orienting to and contacting pheromone source in $30 \mathrm{~min}$ ) +0.50 (number of mating attempts with pheromone source in $30 \mathrm{~min}$ )

$\mathrm{IMR}_{\text {model }}=0.15$ (number of males orienting to a test area in 30 $\min )+0.35$ (number of males orienting to and contacting visual model in $30 \mathrm{~min}$ ) +0.50 (number of mating attempts with visual model in $30 \mathrm{~min}$ )

$\mathrm{IMR}_{\text {total }}=\mathrm{IMR}_{\text {pheromone }}+\mathrm{IMR}_{\text {model }}$

\section{Effect of presence of visual stimulus}

In this experiment, the behaviour of T. ampellophaga males to a pheromone source alone and a normal cardboard model fixed to a pheromone source by a pin were compared. Both stimuli were placed $5 \mathrm{~cm}$ apart in a line perpendicular to the wind direction. This visual model was used only in this experiment.

\section{Effect of the spatial distribution of the visual model and pheromone source}

Experiments with the following spatial configurations between the olfactory and visual stimuli (dummy female) were performed: (1) visual model was placed downwind of the pheromone source at different distances; (2) visual model was placed upwind of the pheromone source at different distances; and (3) pheromone source and visual model were placed at different distances in a line perpendicular to the wind direction. For each experiment, the distance between stimuli was increased until all male copulatory attempts were found to be directed to only one of them.

\section{Effect of the characteristics of female visual model}

This experiment consisted of series of sub-experiments, each involving a pair of visual models, placed $2 \mathrm{~cm}$ apart on the experimental platform with a pheromone stimulus put $2 \mathrm{~cm}$ upwind of the center of the line between the two models.

\section{Dimensions of visual model}

The following 3-dimentional cardboard models of female $T$. ampellophaga were compared: normal model $(12 / 21 \mathrm{~mm}), 1.5 \times$ normal model $(18 / 36 \mathrm{~mm})$ and $2 \times \operatorname{normal}$ model $(25 / 50 \mathrm{~mm})$. Each model was fixed to a grey rubber bottle cap. All possible model combinations were tested. 


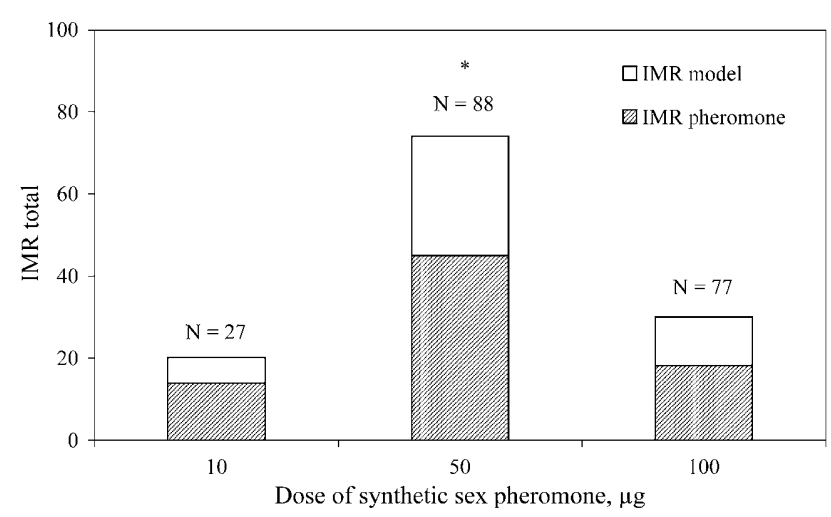

Fig. 2. Index of male responses of T. ampellophaga males to a dummy female and a pheromone stimulus presented at different doses. $\mathrm{N}=$ total number of moths orienting to the test area in $30 \mathrm{~min}$. Columns with no star are not significantly different according to $\chi^{2}$ test, $\mathrm{P}<0.001$. There are not significant differences between $\mathrm{IMR}_{\text {pheromone }}$ and $\mathrm{IMR}_{\text {model }}$ for each pheromone treatment.

\section{Shape of visual model}

Four 2-dimensional models of different shape were made of black paper and pinned to pieces of cardboard $(2 \times 2 \mathrm{~cm})$ : a triangle $(20 \mathrm{~mm}$ side $)$, a square $(20 \mathrm{~mm}$ side $)$, a rhomb $(20 \mathrm{~mm}$ side) and a circle ( $20 \mathrm{~mm}$ diameter). All possible model combinations were tested.

\section{Colour and posture of visual model}

Black, red and spotted (black model with red spots on wings) normal cardboard models were tested. To establish the role of female posture on male mating behaviour, the normal 3-dimensional cardboard model was compared with the 2-dimensional cardboard model, which imitate calling and "resting" postures, respectively (see Hallberg \& Subchev, 1997; Toshova \& Subchev, 2003). Each model was fixed to a grey rubber vial cap.

\section{Sex and species}

In this experiment, we observed the behaviour of T. ampellophaga males to: (1) a pair of dead conspecific female and male moths; and (2) pairs of dead male moths of different species, members of subfamily Procridinae $-T$. ampellophaga, Rhagades pruni Denis \& Schiffermüller and Illiberis rotundata Jordan, in all possible combinations.

\section{Data recording}

In each experiment (except Experiment I), observations continued until 20 males attempted to copulate with either the pheromone or visual stimulus. The number of contacts and mating attempts at each stimulus (chemical or visual) was recorded. The contact was scored as successful when the male moth touched the stimulus with its tarsi or antennae. Scored as mating were cases where a male landed on the treatment and remained for at least $2 \mathrm{~s}$ wing fanning and curving of its abdomen towards the stimulus in an attempt to copulate. Mating attempt duration was recorded only in Experiment II and Experiment IV.

For statistical analyses, SPSS for Windows, Release 11.0.1 (SPSS Inc.) was used. A chi square goodness-of-fit test was used to detect significant differences in number of responding males (presented as percentage) to the stimuli and between the IMRs.

Data, involving the duration of the copulatory attempts, were statistically analyzed using one-way analysis of variance

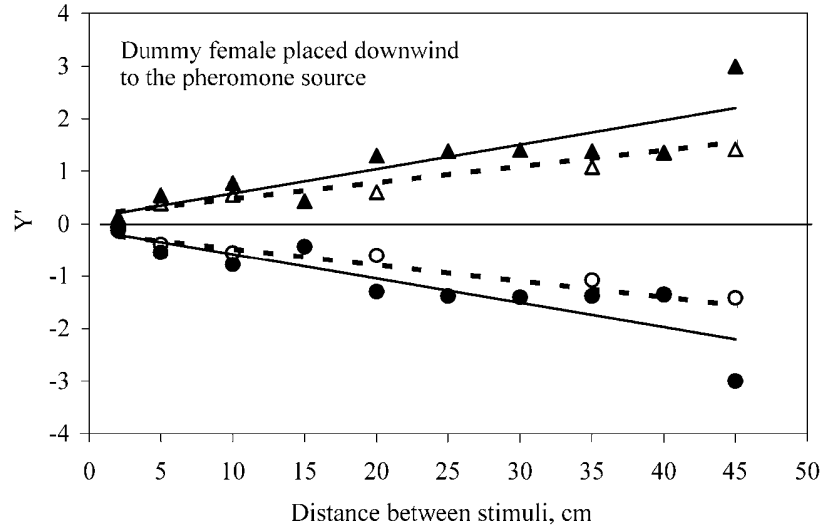

Fig. 3. Relationship between transformed proportion of behavioural responses of $T$. ampellophaga males and the distance between the olfactory and visual stimuli. Open triangles: contacts with pheromone stimulus $\left(\mathrm{y}=0.03 \mathrm{x}+0.17, \mathrm{r}^{2}=0.81\right.$, $\mathrm{P}=0.001)$; filled triangles: copulatory attempts with pheromone stimulus $\left(\mathrm{y}=0.05 \mathrm{x}+0.12, \mathrm{r}^{2}=0.74, \mathrm{P}=0.001\right)$; open circles: contacts with visual model $\left(\mathrm{y}=-0.03 \mathrm{x}-0.17, \mathrm{r}^{2}=0.81, \mathrm{P}=\right.$ 0.001 ); filled circles: copulatory attempts with visual model (y $\left.=-0.05 \mathrm{x}-0.12, \mathrm{r}^{2}=0.74, \mathrm{P}=0.001\right)$. The lines are regressions of responses of males on the distance between the pheromone stimulus and visual model: dashed lines - contacts; solid lines copulatory attempts.

(ANOVA) followed by comparison of means using the StudentNewman-Keuls test after a significant ANOVA.

A regression analysis was applied to define spatial relationships (Figs 3-5 below). Percentage of male contacts and copulatory attempts with stimuli tested were subjected to logarithmic transformation prior to analysis: $\mathrm{Y}^{\prime}=\log (\mathrm{Y} /(100-\mathrm{Y}))$, where $\mathrm{Y}$ is a percentage of behavioural responses.

\section{RESULTS}

Oriented flight of wild T. ampellophaga males was observed at distances of more than $10 \mathrm{~m}$ from the experimental area at a height of more than $3 \mathrm{~m}$. After approaching the platform, the moths touched its surface and approximately $90 \%$ of them landed on its downwind edge. A very small percentage of males landed a few centimeters upwind from this edge or on leaves of the surrounding vines. Male moths that approached the platform often flew away and reoriented to it. When the moths were on the surface of the platform, they walked upwind, fluttered their wings and moved their antennae. The next behavioural step, contact, involved touching the stimulus (chemical or visual) with antennae or tarsi. Male copulatory attempts included curving the abdomen towards the stimulus and exposing their genitalia in a trial to copulate. Sometimes the simultaneous presence at the stimulus of two or more males resulted in homocourtships. Male moths were observed to attempt copulation with each other on the pheromone stimulus or visual model, or surface of the platform near the both stimuli.

\section{Effect of pheromone dose}

Generally, there was no significant difference between the $\mathrm{IMR}_{\text {pheromone }}$ and $\mathrm{IMR}_{\text {model }}$ in each treatment. The omnibus chi-square yielded significant differences among total IMRs $\left(\chi^{2}=39.94 ; \mathrm{df}=2 ; \mathrm{P}<0.001\right)$. Pairwise post 


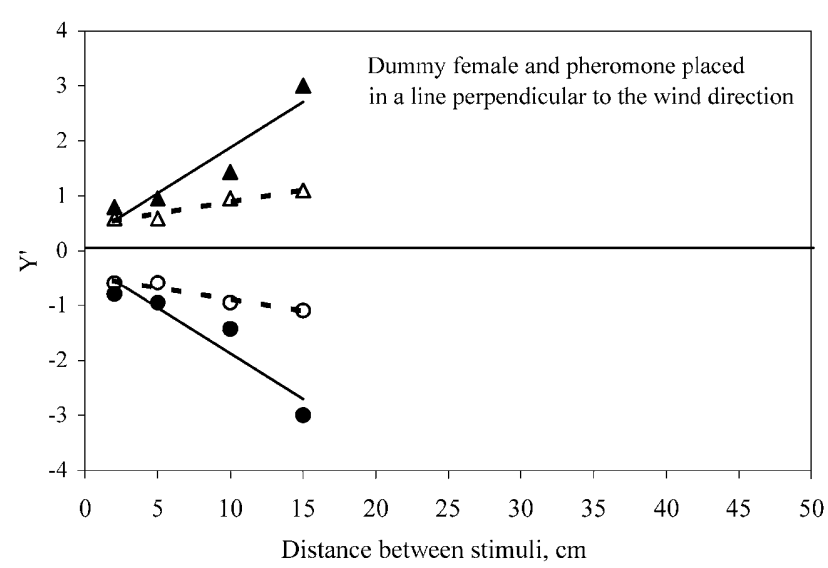

Fig. 4. Relationship between transformed proportion of behavioural responses of $T$. ampellophaga males and the distance between the olfactory and visual stimuli. Open triangles: contacts with pheromone stimulus $\left(y=0.04 x+0.46, \mathrm{r}^{2}=0.93\right.$, $\mathrm{P}=0.035$ ); filled triangles: copulatory attempts with pheromone stimulus $\left(\mathrm{y}=0.17 \mathrm{x}+0.22, \mathrm{r}^{2}=0.88, \mathrm{P}=0.06\right)$; open circles: contacts with visual model $\left(\mathrm{y}=-0.04 \mathrm{x}-0.46, \mathrm{r}^{2}=0.93, \mathrm{P}=\right.$ 0.035 ); filled circles: copulatory attempts with visual model ( $\mathrm{y}$ $\left.=-0.17 \mathrm{x}-0.22, \mathrm{r}^{2}=0.88, \mathrm{P}=0.06\right)$. The lines are regressions of responses of males on the distance between the pheromone stimulus and visual model: dashed lines - contacts; solid lines copulatory attempts.

hoc testing showed that the total IMR of the treatment where the pheromone was tested at a dose of $50 \mu \mathrm{g}$ was significantly higher than that for the lower $(10 \mu \mathrm{g})\left(\chi^{2}=\right.$ 31.02; $\mathrm{df}=1 ; \mathrm{P}<0.001)$ and higher doses $(100 \mu \mathrm{g})\left(\chi^{2}=\right.$ $18.62 ; \mathrm{df}=1 ; \mathrm{P}<0.001)$ of the synthetic sex pheromone. Although the number of male moths that oriented to the treatment with the higher dose of pheromone $(100 \mu \mathrm{g})$ was more than twice that for the lower dose $(10 \mu \mathrm{g})$, there was no significant difference between these two total IMRs. (Fig. 2.)

\section{Effect of presence of visual stimulus}

The percentage of contacts $(64.3 \%)$ and copulatory attempts $(64.0 \%)$ of male moths with female visual model plus pheromone was significantly higher than for the pheromone stimulus alone $(35.7 \%$ and $36.0 \%$ respectively) $\left(\chi^{2}=7.84\right.$; $\left.\mathrm{df}=1 ; \mathrm{P}<0.01\right)$. However, the dura-

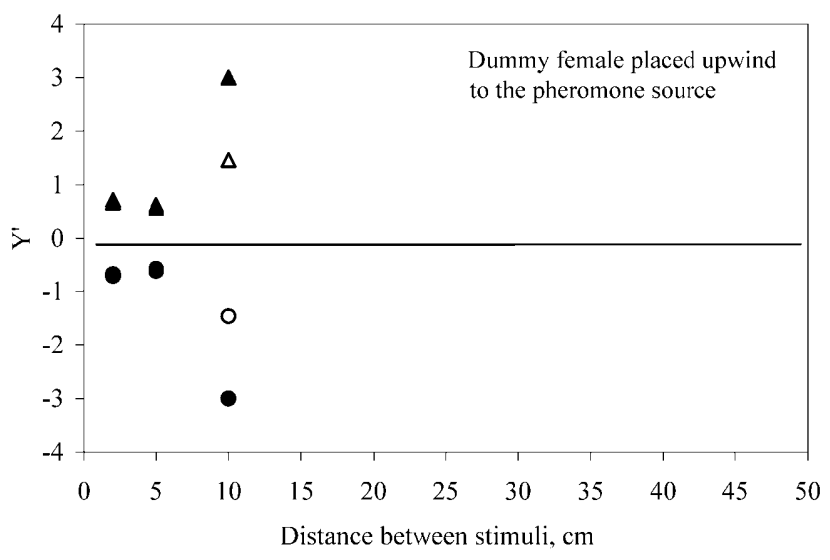

Fig. 5. Relationship between transformed proportion of behavioural responses of $T$. ampellophaga males and the distance between the olfactory and visual stimuli. Open triangles: contacts with pheromone stimulus $\left(y=0.11 \mathrm{x}+0.29, \mathrm{r}^{2}=0.79\right.$, $\mathrm{P}=0.307)$; filled triangles: copulatory attempts with pheromone stimulus $\left(\mathrm{y}=0.31 \mathrm{x}-0.28, \mathrm{r}^{2}=0.84, \mathrm{P}=0.265\right)$; open circles: contacts with visual model $\left(\mathrm{y}=-0.11 \mathrm{x}-0.29, \mathrm{r}^{2}=0.79, \mathrm{P}=\right.$ $0.307)$; filled circles: copulatory attempts with visual model (y $\left.=0.31 \mathrm{x}-0.28, \mathrm{r}^{2}=0.84, \mathrm{P}=0.265\right)$.

tion of the copulatory attempts of the males were similar for both the pheromone stimulus alone and pheromone plus visual model $(32.8 \pm 8.5 \mathrm{~s}$ and $25.6 \pm 8.9 \mathrm{~s}$, respectively; $\mathrm{P}=0.603$; one-way ANOVA analysis).

\section{Effect of the spatial distribution of the visual model and pheromone source}

Generally, the percentage of males responding to models decreased with distance between dummy female and pheromone source, regardless of the spatial arrangement of these stimuli (Figs 3-5). For the configuration where the dummy female was placed downwind of the pheromone source, the greatest distance from the pheromone source at which males still attempted copulation with the dummy female, was $40 \mathrm{~cm}$ (Fig. 3). When the chemical and visual stimuli were placed in a line perpendicular to the wind direction or in the reverse position, this distance was four- to eightfold times shorter, respectively (Figs 4-5).

TABLE 1. Behavioural responses of T. ampellophaga males in the field to a source of synthetic sex pheromone combined with two cardboard models of different dimensions.

\begin{tabular}{|c|c|c|c|c|c|c|c|c|c|c|c|c|c|c|c|}
\hline \multirow{2}{*}{\multicolumn{3}{|c|}{$\begin{array}{c}\text { Stimuli compared } \\
\text { Dimension of model, mm }\end{array}$}} & \multicolumn{4}{|c|}{ Contacts } & \multicolumn{4}{|c|}{ Copulatory attempts } & \multicolumn{5}{|c|}{ Copulatory duration, $\mathrm{s}$} \\
\hline & & & \multirow{2}{*}{$\mathrm{N}$} & \multicolumn{3}{|c|}{$\%$ response $^{\mathrm{a}}$} & \multirow{2}{*}{$\mathrm{N}$} & \multicolumn{3}{|c|}{$\%$ response $^{\mathrm{a}}$} & \multirow{2}{*}{$\mathrm{N}$} & \multicolumn{3}{|c|}{ mean \pm S.E. } & \multirow{2}{*}{ P-value ${ }^{b}$} \\
\hline A & B & $\mathrm{C}$ & & $\mathrm{A}$ & $\mathrm{B}$ & $\mathrm{C}$ & & $\mathrm{A}$ & B & $\mathrm{C}$ & & A & $\mathrm{B}$ & $\mathrm{C}$ & \\
\hline $\begin{array}{c}\text { normal } \\
10 / 20\end{array}$ & $\begin{array}{c}1.5 \mathrm{x} \\
18 / 36\end{array}$ & $\begin{array}{l}\text { phero- } \\
\text { mone }\end{array}$ & 61 & $24.6 \mathrm{~b}$ & $23.0 \mathrm{~b}$ & $52.4 \mathrm{a}$ & 56 & $21.4 \mathrm{~b}$ & $23.2 b$ & $55.4 \mathrm{a}$ & 40 & $\mathbf{2 . 0} \pm 0.0$ & $\mathbf{2 . 5} \pm 0.2$ & $\mathbf{4 2 . 8}^{*} \pm 8.9$ & $<0.001$ \\
\hline $\begin{array}{c}\text { normal } \\
10 / 20\end{array}$ & $\begin{array}{c}2 \mathrm{x} \\
25 / 50\end{array}$ & $\begin{array}{l}\text { phero- } \\
\text { mone }\end{array}$ & 44 & $25.0 \mathrm{~b}$ & $25.0 \mathrm{~b}$ & $50.0 \mathrm{a}$ & 43 & $23.3 b$ & $27.9 b$ & $48.8 \mathrm{a}$ & 40 & $\mathbf{2 . 9} \pm 0.6$ & $3.2 \pm 0.7$ & $17.1^{*} \pm 3.1$ & $<0.001$ \\
\hline $\begin{array}{c}1.5 \mathrm{x} \\
18 / 36\end{array}$ & $\begin{array}{c}2 \mathrm{x} \\
25 / 50\end{array}$ & $\begin{array}{l}\text { phero- } \\
\text { mone }\end{array}$ & 57 & $14.1 \mathrm{c}$ & $29.8 b$ & $56.1 \mathrm{a}$ & 36 & $2.7 \mathrm{c}$ & $16.7 \mathrm{~b}$ & $80.6 \mathrm{a}$ & 21 & 5.0 & $4.7 \pm 2.2$ & $10.8 \pm 2.3$ & $>0.05$ \\
\hline
\end{tabular}

Pheromone $=$ pheromone source without a visual model. Figures followed by the same letter in a row for each behavioural category are not significantly different at $\mathrm{P}<0.05, \chi^{2}$ test. ${ }^{a}$ Responses are based on behaviour of 20 males in each experiment. ${ }^{b}$ Probability value of differences within each group calculated using one-way ANOVA analysis. *Significant difference in response to pheromone at $\mathrm{P}<0.05$ according to Student-Newman-Keuls test. 
TABLE 2. Behavioural responses of T. ampellophaga males in the field to a source of synthetic sex pheromone combined with two cardboard models of different shapes.

\begin{tabular}{|c|c|c|c|c|c|c|c|c|c|c|c|c|c|c|c|}
\hline \multirow{2}{*}{\multicolumn{3}{|c|}{ Stimuli compared }} & \multicolumn{4}{|c|}{ Contacts } & \multicolumn{4}{|c|}{ Copulatory attempts } & \multicolumn{5}{|c|}{ Copulatory duration, $\mathrm{s}$} \\
\hline & & & \multirow{2}{*}{$\mathrm{N}$} & \multicolumn{3}{|c|}{$\%$ response $^{\mathrm{a}}$} & \multirow{2}{*}{$\mathrm{N}$} & \multicolumn{3}{|c|}{$\%$ response $^{\mathrm{a}}$} & \multirow{2}{*}{$\mathrm{N}$} & \multicolumn{3}{|c|}{ mean \pm S.E. } & \multirow{2}{*}{ P-value ${ }^{b}$} \\
\hline A & $\mathrm{B}$ & $\mathrm{C}$ & & $\mathrm{A}$ & $\mathrm{B}$ & $\mathrm{C}$ & & A & $\mathrm{B}$ & $\mathrm{C}$ & & A & B & $\mathrm{C}$ & \\
\hline$\triangle$ & $\square$ & $\begin{array}{l}\text { phero- } \\
\text { mone }\end{array}$ & 47 & $19.2 b$ & $25.5 b$ & $55.3 \mathrm{a}$ & 32 & $12.5 b$ & $15.6 \mathrm{~b}$ & $71.9 \mathrm{a}$ & 32 & $2.5 \pm 0.3$ & $\mathbf{3 . 4} \pm 0.9$ & $8.6 \pm 1.5$ & $>0.05$ \\
\hline$\triangle$ & 0 & $\begin{array}{l}\text { phero- } \\
\text { mone }\end{array}$ & 33 & $24.3 \mathrm{~b}$ & $33.3 \mathrm{ab}$ & $42.4 \mathrm{a}$ & 28 & $28.6 \mathrm{a}$ & $32.1 \mathrm{a}$ & $39.3 \mathrm{a}$ & 25 & $2.3 \pm 0.2$ & $2.4 \pm 0.3$ & $\mathbf{3 . 0} \pm 0.7$ & $>0.05$ \\
\hline$\square$ & $\bigcirc$ & $\begin{array}{l}\text { phero- } \\
\text { mone }\end{array}$ & 39 & $15.4 \mathrm{c}$ & $33.3 b$ & $51.3 \mathrm{a}$ & 32 & $12.5 \mathrm{c}$ & $28.1 \mathrm{~b}$ & $59.4 \mathrm{a}$ & 27 & $\mathbf{2 . 8} \pm 0.6$ & $\mathbf{2 . 3} \pm 0.2$ & $15.9 * \pm 3.7$ & $<0.01$ \\
\hline$\triangle$ & $\diamond$ & $\begin{array}{l}\text { phero- } \\
\text { mone }\end{array}$ & 48 & $18.7 \mathrm{~b}$ & $29.2 b$ & $52.1 \mathrm{a}$ & 38 & $18.4 \mathrm{~b}$ & $21.1 \mathrm{~b}$ & $60.5 \mathrm{a}$ & 37 & $3.4 \pm 0.5$ & $3.6 \pm 0.7$ & $\mathbf{2 3 . 0} * \pm 4.3$ & $<0.01$ \\
\hline$\square$ & $\diamond$ & $\begin{array}{l}\text { phero- } \\
\text { mone }\end{array}$ & 44 & $22.7 b$ & $22.7 b$ & $54.6 \mathrm{a}$ & 38 & $21.1 \mathrm{~b}$ & $21.1 \mathrm{~b}$ & $57.8 \mathrm{a}$ & 33 & $\mathbf{3 . 0} \pm 0.6$ & $4.3 \pm 1.2$ & $17.9^{*} \pm 3.1$ & $<0.01$ \\
\hline$\diamond$ & 0 & $\begin{array}{l}\text { phero- } \\
\text { mone }\end{array}$ & 39 & $12.8 \mathrm{~b}$ & $23.1 \mathrm{~b}$ & $64.1 \mathrm{a}$ & 29 & $6.9 \mathrm{c}$ & $31.0 \mathrm{~b}$ & $62.1 \mathrm{a}$ & 24 & $\mathbf{2 . 0} \pm 0.0$ & $3.4 \pm 0.6$ & $\mathbf{1 8 . 9} \pm 5.5$ & $>0.05$ \\
\hline
\end{tabular}

Pheromone $=$ pheromone source without a visual model. Figures followed by the same letter in a row for each behavioural category are not significantly different at $\mathrm{P}<0.05, \chi^{2}$ test. ${ }^{a}$ Responses are based on behaviour of 20 males in all experiments. ${ }^{b}$ Probability value of differences within each group calculated using one-way ANOVA analysis. *Significant difference in response to pheromone at $\mathrm{P}<0.05$ according to Student-Newman-Keuls test.

When the dummy female was placed downwind of the chemical source, there was a significant positive regression between the percentage of male contacts and copulatory attempts with the pheromone stimulus and the distance between these stimuli, olfactory and visual, respectively. An inverse regression was found between the percentages of male behavioural responses to the visual cue and the distance from the pheromone source (Fig. 3).

For the configurations where the dummy female and pheromone emitter where placed in a line perpendicular to the wind direction, similar patterns were also found in the percentage of male contacts with the olfactory and visual stimuli. However, there was no significant regression of between distance and percentage of male copulatory attempts (Fig. 4).

When the dummy female was placed upwind of the chemical stimulus, there was no significant regression relationship between the percentages of male responses and the distance between the stimuli (Fig. 5).

\section{Effect of characteristics of female visual model}

Generally, analysis of the behaviour of male T. ampellophaga to the pheromone combined with two different visual models, regardless of the model feature tested, showed that the olfactory stimulus strongly influenced the behavioural responses of male moths - it received considerably more contacts and copulatory attempts than the visual models. As a whole, males spent longer attempting to copulate with the rubber dispenser containing the pheromone than with the models (Table 1-4).

\section{Dimension of visual model}

There were no significant differences in male responses to the normal and $1.5 \times$ normal models or the normal and the largest models. Male moths preferably contacted and attempted to copulate with the $2 \times$ normal model com-

TABLE 3. Behavioural responses of T. ampellophaga males in the field to a source of synthetic sex pheromone combined with two cardboard models of different colour and posture.

\begin{tabular}{|c|c|c|c|c|c|c|c|c|c|c|c|c|c|c|c|}
\hline \multirow{2}{*}{\multicolumn{3}{|c|}{ Stimuli compared }} & \multicolumn{4}{|c|}{ Contacts } & \multicolumn{4}{|c|}{ Copulatory attempts } & \multicolumn{5}{|c|}{ Copulatory duration, $\mathrm{s}$} \\
\hline & & & \multirow{2}{*}{$\mathrm{N}$} & \multicolumn{3}{|c|}{$\%$ response $^{\mathrm{a}}$} & \multirow{2}{*}{$\mathrm{N}$} & \multicolumn{3}{|c|}{$\%$ response $^{\mathrm{a}}$} & \multirow{2}{*}{$\mathrm{N}$} & \multicolumn{3}{|c|}{ mean \pm S.E. } & \multirow{2}{*}{ P-value } \\
\hline A & $\mathrm{B}$ & $\mathrm{C}$ & & A & $\mathrm{B}$ & $\mathrm{C}$ & & $\mathrm{A}$ & $\mathrm{B}$ & $\mathrm{C}$ & & A & $\mathrm{B}$ & $\mathrm{C}$ & \\
\hline black & red & $\begin{array}{l}\text { phero- } \\
\text { mone }\end{array}$ & 49 & $24.5 b$ & $14.3 \mathrm{~b}$ & $61.2 \mathrm{a}$ & 30 & $6.7 b$ & 0.0 & $93.3 \mathrm{a}$ & 19 & $4.0 \pm 1.0$ & 0.0 & $\mathbf{1 4 . 9} \pm 2.2$ & $>0.05$ \\
\hline black & spotted & $\begin{array}{l}\text { phero- } \\
\text { mone }\end{array}$ & 36 & $19.4 \mathrm{~b}$ & $16.7 \mathrm{~b}$ & $63.9 \mathrm{a}$ & 23 & 0.0 & $4.3 b$ & $95.7 \mathrm{a}$ & 15 & 0.0 & 10 & $17.1 \pm 3.4$ & na \\
\hline red & spotted & $\begin{array}{l}\text { phero- } \\
\text { mone }\end{array}$ & 49 & $8.2 b$ & $38.7 \mathrm{a}$ & $53.1 \mathrm{a}$ & 35 & 0.0 & $28.6 b$ & $71.4 \mathrm{a}$ & 32 & 0.0 & $2.7 \pm 0.3$ & $\mathbf{1 8 . 4} \pm 3.8$ & $<0.05$ \\
\hline "calling" & "resting" & $\begin{array}{c}\text { phero- } \\
\text { mone }\end{array}$ & 27 & $22.2 \mathrm{~b}$ & $7.4 \mathrm{c}$ & $70.4 \mathrm{a}$ & 27 & $22.2 b$ & $7.4 \mathrm{c}$ & $70.4 \mathrm{a}$ & 25 & $\mathbf{3 . 0} \pm 0.3$ & $\mathbf{2 . 0} \pm 0.0$ & $9.2 \pm 2.1$ & $>0.05$ \\
\hline
\end{tabular}

Pheromone $=$ pheromone source without a visual model. Figures followed by the same letter are not significantly different at $\mathrm{P}<$ $0.05, \chi^{2}$ test. ${ }^{a}$ Responses are based on behaviour of 20 males in each experiment. ${ }^{b}$ Probability value of differences within each group calculated using one-way ANOVA analysis. $\mathrm{na}=$ statistical analysis is not applicable. 
TABLE 4. Behavioral responses of T. ampellophaga males to a source of synthetic sex pheromone in combination with two dead moths of different sex and species in the field.

\begin{tabular}{|c|c|c|c|c|c|c|c|c|c|c|c|c|c|c|c|}
\hline \multirow{2}{*}{\multicolumn{3}{|c|}{ Stimuli compared }} & \multicolumn{4}{|c|}{ Contacts } & \multicolumn{4}{|c|}{ Copulatory attempts } & \multicolumn{5}{|c|}{ Copulatory duration, $\mathrm{s}$} \\
\hline & & & \multirow{2}{*}{$\mathrm{N}$} & \multicolumn{3}{|c|}{$\%$ response $^{\mathrm{a}}$} & \multirow{2}{*}{$\mathrm{N}$} & \multicolumn{3}{|c|}{$\%$ response $^{\mathrm{a}}$} & \multirow{2}{*}{$\mathrm{N}$} & \multicolumn{3}{|c|}{ mean \pm S.E. } & \multirow{2}{*}{ P-value } \\
\hline A & $\mathrm{B}$ & $\mathrm{C}$ & & A & $\mathrm{B}$ & $\mathrm{C}$ & & A & $\mathrm{B}$ & $\mathrm{C}$ & & A & $\mathrm{B}$ & $\mathrm{C}$ & \\
\hline 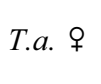 & T.a. $\boldsymbol{\delta}^{-}$ & $\begin{array}{l}\text { phero- } \\
\text { mone }\end{array}$ & 39 & $41.0 \mathrm{a}$ & $7.7 \mathrm{~b}$ & $51.3 \mathrm{a}$ & 33 & $36.3 b$ & $6.1 \mathrm{c}$ & $57.6 \mathrm{a}$ & 32 & $4.1 \pm 0.7$ & $3.5 \pm 1.5$ & $27.2 * \pm 6.5$ & $<0.05$ \\
\hline T.a. $0^{+}$ & R.p. $\sigma^{\pi}$ & $\begin{array}{l}\text { phero- } \\
\text { mone }\end{array}$ & 44 & $34.1 \mathrm{~b}$ & $9.1 \mathrm{c}$ & $56.8 \mathrm{a}$ & 37 & $24.3 \mathrm{~b}$ & $8.1 \mathrm{c}$ & $67.6 \mathrm{a}$ & 29 & $\mathbf{3 . 0} \pm 0.6$ & 5.0 & $9.8 \pm 1.5$ & $<0.05$ \\
\hline T.a. $\widehat{0}$ & I.r. $\hat{o}$ & $\begin{array}{l}\text { phero- } \\
\text { mone }\end{array}$ & 46 & $19.6 b$ & $26.1 \mathrm{~b}$ & $54.3 \mathrm{a}$ & 30 & $20.0 \mathrm{~b}$ & 0.0 & $80.0 \mathrm{a}$ & 29 & $\mathbf{4 . 8} \pm 0.8$ & 0.0 & $14.8 \pm 2.4$ & $>0.05$ \\
\hline R.p. $\boldsymbol{\delta}^{-}$ & I.r. 0 & $\begin{array}{l}\text { phero- } \\
\text { mone }\end{array}$ & 35 & $17.1 \mathrm{~b}$ & $20.0 \mathrm{~b}$ & $62.9 \mathrm{a}$ & 32 & $12.6 \mathrm{~b}$ & $18.8 \mathrm{~b}$ & $68.8 \mathrm{a}$ & 23 & $\mathbf{3 . 0} \pm 0.4$ & $\mathbf{2 . 0} \pm 0.0$ & $14.5^{*} \pm 2.7$ & $<0.01$ \\
\hline
\end{tabular}

Pheromone $=$ pheromone source without a visual model. Figures followed by the same letter in a row for each behavioral category

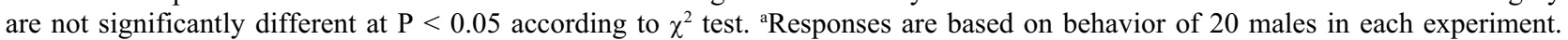
${ }^{b}$ Probability value of differences within each group calculated using one-way ANOVA analysis. *Significant difference in response to pheromone at $\mathrm{P}<0.05$ according to Student-Newman-Keuls test.

pared with the $1.5 \times$ normal model. The mean duration of the mating attempts with the pheromone stimuli was significantly higher than with both models in the combinations: normal and $1.5 \times$ normal models, and normal and largest models $(\mathrm{P}<0.001$, Student-Newman-Keuls test) (Table 1).

\section{Shape of visual model}

The results of the analysis of the behaviour of males to visual models of different shapes revealed significantly higher number of copulatory attempts with the circular compared to the square model $\left(\chi^{2}=5.49 ; \mathrm{df}=1 ; \mathrm{P}=\right.$ $0.02)$, and circular compared to the rhombus model $\left(\chi^{2}=\right.$ 15.16; df $=1 ; \mathrm{P}<0.001)$ (Table 2).

\section{Colour and posture of visual model}

In the paired comparisons of the visual models of different colour, the red model was less effective in evoking mating behaviour than black and spotted ones - males did not attempt to copulate with the red model, although they did touch it (Table 3).

Significantly higher percentages of male behavioural responses were directed to the female model in calling posture compared to that in the resting posture $\left(\chi^{2}=7.76\right.$; $\mathrm{df}=1 ; \mathrm{P}=0.005)$ (Table 3 ).

Sex and species

Dead $T$. ampellophaga female evoked a significantly higher percentage of contacts and mating attempts than dead conspecific male $\left(\chi^{2}=22.22 ; \mathrm{df}=1\right.$; and $\chi^{2}=21.43$; df $=1 ; \mathrm{P}<0.001$, respectively). Similarly, T. ampellophaga males preferably contacted $\left(\chi^{2}=14.54\right.$; $\mathrm{df}=1 ; \mathrm{P}<$ $0.001)$ and made copulatory attempts $\left(\chi^{2}=8.0 ; \mathrm{df}=1 ; \mathrm{P}\right.$ $<0.01$ ) with conspecific male moth than dead $R$. pruni male. The difference in the number of $T$. ampellophaga male contacts with dead conspecific and $I$. rotundata males was not significant $\left(\chi^{2}=0.78 ; \mathrm{df}=1 ; \mathrm{P}=0.38\right)$ but they only attempted to mate with conspecific males. Responses of male $T$. ampellophaga moths to dead $R$. pruni and $I$. rotundata males were not significantly different (Table 4).

\section{DISCUSSION}

The walking movements of male T. ampellophaga after landing on the substrate on which the olfactory and visual cues were placed, probably mediated the final steps of male premating behaviour. Such walking responses are described as part of the premating behaviour of several lepidopteran species and are considered to be a critical element in the location of females (see Charlton \& Cardé, 1990a).

Our observations on the behaviour of $T$. ampellophaga males in the field indicate that a combination of olfactory and visual cues evoked a significantly higher number of male copulatory attempts compared to the olfactory cue presented alone (Experiment II). The results of the experiments in which pheromone and visual stimuli were spatially separated clearly demonstrate the primary role of the pheromone cue in mate location and evoking copulatory behaviour in $T$. ampellophaga males - males preferably contacted and tried mating with the olfactory source. Visual cues seemed to be less important and only elicited copulatory reactions in the immediate proximity of the pheromone stimulus or at a longer distance only if the males continuously received pheromone stimulation. This agrees with the findings of Charlton \& Cardé (1990a) who report that when the female model was placed 5 or $10 \mathrm{~cm}$ from the pheromone bait, male $L$. dispar required significantly more time to contact the female model than to contact the chemical stimulus. The authors report that male gypsy moths need longer to locate females upwind or below the pheromone dispenser compared to when presented with the opposite distributions of both stimuli. An earlier study (Doane, 1968) on the gypsy moth showed that males readily locate a female positioned $15 \mathrm{~cm}$ downwind of a calling female and did not respond to a female placed $15 \mathrm{~cm}$ upwind of a pheromone source. Zagatti \& Renou (1984) report that visual stimuli are included in mate location by $Z$. filipendulae (Zygaeninae) males only at a close distance $(<50 \mathrm{~cm})$ to the pheromone source. In contrast, Epstein at al. (1999) report that vision plays a critical role in the mate finding 
behaviour of $Z$. trifolii in the first hours of the period of mating activity. Z. trifolii males also exploit chemical cues in mate recognition, but only in late afternoon.

As expected, the higher doses of pheromone (50 and $100 \mu \mathrm{g}$ ) in our experiments resulted in a higher number of T. ampellophaga males orientating to the test area. Traps baited with $100 \mu \mathrm{g}$ of the synthetic sex pheromone caught 2-3 times more males than those baited with only $10 \mu \mathrm{g}$ (Subchev et al., 1998). Surprisingly, the highest dose tested $(100 \mu \mathrm{g})$ evoked a reduction in the total number of contacts and copulatory attempts, which are comparable with those obtained with the $10 \mu \mathrm{g}$ dose. The highest number of contacts and mating attempts are observed when both stimuli (olfactory and visual) were applied in the treatment with the middle dose. We hypothesize that this ethological effect of pheromone dose could be due to a difference in the initial burst in emission rates.

The absence of a small female model in our choice experiments did not allow a precise conclusion about the influence of the size of a female on the copulatory behaviour of male $T$. ampellophaga. In lepidopterans, the large female models evoke faster copulatory reactions or a higher number of contacts and copulatory attempts. For example, Shorey \& Gaston (1970) report that in a laboratory female models $1 / 2$ or $1 / 4$ normal size receive a lower percentage of orientations and copulatory attempts by Trichoplusia ni (Hübner) males than normal sized models. Charlton \& Cardé (1990b) demonstrated that cylindrical models comparable in size or larger than $L$. dispar females, evoke significantly longer durations of contact and probing by conspecific males than smaller models. The latter authors explain the effectiveness of the larger models as due to the presence of additional tactile stimuli (female abdominal scales applied on the model). Mate choice based on body size is well documented in the animal kingdom. Male preference for larger females as mating partners has been demonstrated in several insect species (Polak \& Brown, 1995; Harari et al., 1999; Hughes et al., 2000; Lauzière et al., 2000; Logan et al., 2001; Sagarra et al., 2001; Honěk, 2003; Saeki et al., 2005). Usually there is a positive association between female body size and fecundity. In T. ampellophaga, large females could serve as a possible indicator of fecundity and, hence of increased reproductive success.

We found that the colour of female models only influenced the copulatory behaviour of the vine bud moth. Male moths did not differentiate between the solid black model, which is close to the natural colour of this species, from the black model with red spots, but the red colour seemed to inhibit mating after contact with the model. Similarly, Zagatti \& Renou (1984) found that models painted in a combination of colours typical of the genus Zygaena were contacted more frequantly by $Z$. filipendulae males than one-coloured models. In addition, field experiments conducted by Hidaka (1972) showed that Hyphantria cunea Drury males prefered white female models (main natural colour of the moths of this species) compared to blue models. The combination of volatile compounds of Knautia arvensis flowers and a visual stimulus of ultramarine blue elicited feeding behaviour in Z. trifolii moths (Naumann et al., 1991). Similar synergism between olfactory and visual cues is critical in the nectar feeding behaviour of laboratory-reared and wild Manduca sexta L (Sphingidae) (Raguso \& Willis, 2002, 2005). Comparing nectar foraging of two other hawkmoths, Balkenius \& Ros (2006) found that the behaviour of the diurnal species, Macroglossum stellatarum, is strongly affected by a visual cue and that of the nocturnal Deilephila elpenor, by an olfactory stimulus.

Our results indicate that the calling posture of $T$. ampellophaga females is a visual cue for conspecific male recognition. Female posture also releases male copulatory behaviour in $H$. cunea (Hidaka, 1972).

Sex and species belongings strongly influenced the final step in the mating behaviour of male T. ampellophaga - moths copulated preferably with conspecific females than conspecific males, and discriminate between conspecific and heterospecific males. We suggest that the physical characteristics of body scales - their structure or density, mediate mate recognition in $T$. ampellophaga males. A number of researchers have demonstrated the importance of body scales in copulatory behaviour of pheromone-stimulated male moths, and conclude that the stimulatory effect of the scales is due mainly to tactile cues (Shimizu \& Tamaki, 1980; Grant et al., 1987; Charlton \& Cardé, 1990b). However, Zagatti \& Renou (1984) showed that there is not significant difference in the number of contacts of $Z$. filipendulae males with dead conspecific females and dead Zygaena hippocrepidis Hübner females, respectively.

Overall, our field data indicate that mate recognition and successful copulation of male $T$. ampellophaga depends on the joint effect of different stimuli - olfactory, visual and tactile, but the pheromone stimulus appears to be the primary factor mediating this behaviour.

ACKNOWLEDGEMENTS. We are thankful to P. Tenchev (Bulgaria) for preparing the dummy female, and J. Mikulás (Hungary) for allowing access to and use of his private vineyard, and for providing transport to the field. We wish to thank R. van de Ven (Australia) for his helpful comments on the manuscript and revision of the English text. Thanks are due to K. Efetov (Ukraine) for supplying R. pruni pupae and C. Koshio (Japan) for supplying I. rotundata pupae. This work was supported by Grants B-804/1997 and B-1201/2002 of the Bulgarian National Scientific Fund.

\section{REFERENCES}

BAKER T.C. \& LinN C.E. 1984: Wind tunnels in pheromone research. In Hummel H.E. \& Miller T.A. (eds): Techniques in Pheromone Research. Springer, New York, pp. 74-110.

BALKenIus A. \& Ros W. 2006: The relative importance of olfaction and vision in a diurnal and a nocturnal hawkmoth. $J$. Comp. Physiol. (A) 192: 431-437.

CARdÉ R.T. \& Knols B.G.J. 2000: Effects of light levels and plume structure on the orientation manoeuvres of male gypsy moths flying along pheromone plumes. Physiol. Entomol. 25: 141-150.

Cardé R.T \& Mafra-Neto A. 1996: Mechanisms of flight of male moths to pheromone. In Cardé R.T. \& Minks A.K. (eds): 
Insect Pheromone Research: New Directions. Chapman \& Hall, New York, pp. 275-290.

Castrovillo P. \& Cardé R. 1980: Male codling moth (Laspeyresia pomonella) orientation to visual cues in the presence of pheromone and sequences of courtship behaviours. Ann. Entomol. Soc. Am. 73: 100-105.

Charlton R.E. \& CARDÉ R.T. 1990a: Orientation of male gypsy moths, Lymantria dispar (L.), to pheromone sources: the role of olfactory and visual cues. J. Insect Behav. 3: 443-469.

Charlton R.E. \& CARDÉ R.T. 1990b: Factors mediating copulatory behaviour and close-range mate recognition in the male gypsy moth, Lymantria dispar. Can. J. Zool. 68: 1995-2004.

Charlton R.E., Kanno H., Collins R.D. \& Cardé R.T. 1993: Influence of pheromone concentration and ambient temperature on flight of the gypsy moth, Lymantria dispar (L.), in a sustained-flight wind tunnel. Physiol. Entomol. 18: 349-362.

DoANE C.C. 1968: Aspects of the mating behaviour of the gypsy moth. Ann. Entomol. Soc. Am. 61: 768-773.

El-SAYed A.M. 2005: The Pherobase: Database of Insect Pheromones and Semiochemicals. http://www.pherobase.com Epstein M.E., Geertsema H., Naumann C.M. \& Tarmann G.M. 1999: The Zygaenoidea. In Kristensen N.P. (ed.): Handbook of Zoology. Vol. 4. Arthropoda: Insecta, part 35. Lepidoptera, Moths and Butterflies. Vol. 1: Evolution, Systematics, and Biogeography. Walter de Gruyter, Berlin, New York, pp. 159-180.

FARCAS S.R. \& SHOREY H.H. 1974: Mechanisms of orientation to a distant pheromone source. In Birch M.C. (ed.): Pheromones. North-Holland Publishing Company, Amsterdam, pp. 81-95.

Grant G.G., Frech D., MacDonald L., Slessor K.N. \& King G.G.S. 1987: Copulation releaser pheromone in body scales of female whitemarked tussock moth Orgyia leucostigma (Lepidoptera: Lymantriidae): Identification and behavioural role. J. Chem. Ecol. 13: 345-356.

Gross H.R., Carpenter J.E. \& Sparks A.N. 1983: Visual acuity of Heliothis zea (Lepidoptera: Noctuidae) males as a factor influencing the efficiency of pheromone traps. Environ. Entomol. 12: 844-845.

Hallberg E. \& Subchev M. 1997: Unusual location and structure of female pheromone glands in Theresimima (= Ino) ampellophaga Bayle-Barelle, 1808 (Lepidoptera, Zygaenidae). Int. J. Insect Morphol. Embryol. 25: 381-389.

Harari A.R., Handler A.M. \& Landolt P.J. 1999: Sizeassortative mating, male choice and female choice in the curculionid beetle Diaprepes abbreviatus. Anim Behav. 58: 1191-1200.

HidaKa T. 1972: Biology of Hyphantria cunea Drury (Lepidoptera: Arctiidae) in Japan. XIV. Mating behaviour. Appl. Entomol. Zool. 7: 116-132.

HonĚK A. 2003: Body size and mating success in Pyrrhocoris apterus (Heteroptera). Eur. J. Entomol. 100: 55-60.

Hughes L., Chang B.S.-W., Wagner D. \& Pierce N.E. 2000: Effects of mating history on ejaculate size, fecundity, longevity, and copulation duration in the ant-tended lycaenid butterfly, Jalmenus evagoras. Behav. Ecol. Sociobiol. 47: 119-128.

KenNedy J. 1983: Zigzagging and casting as a programmed response to windborne odour: a review. Physiol. Entomol. 8: $109-120$

KUENEN L.P.S. \& BAKER T.C. 1982: The effects of pheromone concentration on the flight behaviour of the oriental fruit moth, Grapholitha molesta. Physiol. Entomol. 7: 423-434.

Lauzière I., Pérez-Lachaud G. \& Brodeur J. 2000: Effect of female body size and adult feeding on the fecundity and longevity of the parasitoid Cephalonomia stephanoderis Betrem (Hymenoptera: Bethylidae). Ann. Entomol. Soc. Am. 93: 103-109.
Logan D.P., Allsopp P.G. \& Zalucki M.P. 2001: Effect of body size on fecundity of Childers canegrub, Antitrogus parvulus Britton (Coleoptera: Scarabaeidae). Austral. J. Entomol. 40: 365-370.

Mafra-Neto A. \& CARdÉ R.T. 1994: Fine-scale structure of pheromone plumes modulates upwind orientation of flying moths. Nature 369: 142-144.

MAFRA-Neto A. \& CARDÉ R.T. 1998: Rate of realized interception of pheromone pulses in different wind speeds modulates almond moth orientation. J. Comp. Physiol. (A) 182: 563-572.

Myerson J., Haddon W.F. \& Soderstrom E.L. 1982: sec-Butyl (Z)-7-tetradecenoate. A novel sex pheromone component from the western grapeleaf skeletonizer, Harrisina brillians. Tetrahedron Lett. 23: 2757-2760.

NaUmanN C.M. 1988: Zur Evolution und adaptiven Bedeutung zweier unterschiedlicher Partnerfindungsstrategien bei Zygaena trifolii (Esper, 1783) (Insecta, Lepidoptera). Verh. Dt. Zool. Ges. 81: 257-258.

NAUMANN C.M. 1990: Stammesgeschichtliche Rekonstruktion und ökologische Beziehungen der Organismen - Ansätze für interdisziplinäre Kooperation. Verh. Dt. Zool. Ges. 83: 291-301.

Naumann C.M., Ockenfels P., Schmitz J., Schmidt F. \& FrancKe W. 1991: Reactions of Zygaena moths to volatile compounds of Knautia arvensis (Lepidoptera: Zygaenidae). Entomol. Gener. 15: 255-264.

PolaK M \& Brown W.D. 1995: Mating tactics and courtship behaviour in Cleogonus rubetra (Fabricius) (Coleoptera: Curculionidae). J. Insect Behav. 8: 453-464.

Preiss R. \& Kramer E. 1986: Anemotactic orientation of gypsy moth males and its modification by the attractant pheromone (+) - disparlure during walking. Physiol. Entomol. 11: 185-198.

Prinz J. \& Naumann C.M. 1988: Optische Parameter bei der Partnerfindung von Zygaena trifolii (Insecta, Lepidoptera). Verh. Dt. Zool. Ges. 81: 258.

Raguso R.A. \& WiLLis M.A. 2002: Synergy between visual and olfactory cues in nectar feeding by naïve hawkmoths, Manduca sexta. Anim. Behav. 64: 685-695.

Raguso R.A. \& Willis M.A. 2005: Synergy between visual and olfactory cues in nectar feeding by wild hawkmoths, Manduca sexta. Anim. Behav. 69: 407-418.

RichERSON J.V. 1977: Pheromone-mediated behaviour of the gypsy moth. J. Chem. Ecol. 3: 291-308.

ROYER L. \& MCNeIL J.N. 1993: Effect of relative humidity conditions on responsiveness of European corn borer (Ostrinia nubilalis) males to female sex pheromone in a wind tunnel. $J$. Chem. Ecol. 19: 61-69.

Saeki Y., Kruse K.C. \& Switzer P.V. 2005: Male preference for large females and female reproductive condition in the Japanese beetle, Popillia japonica Newman (Coleoptera: Scarabaeidae). J. Kansas Entomol. Soc. 78: 13-19.

Sagarra L.A., Vincent C. \& Stewart R.K. 2001: Body size as an indicator of parasitoid quality in male and female Anagyrus kamali (Hymenoptera: Encyrtidae). Bull. Entomol. Res. 91: 363-367.

Schofield S.W., Justus K.A., Mafra-Neto A. \& Cardé R.T. 2003: Flight of male Cadra cautella along plumes of air and pheromone superimposed on backgrounds of pheromone. Entomol. Exp. Appl. 109: 173-181.

Shimizu K. \& TAMAKi Y. 1980: Releasers of male copulatory attempt in the smaller tea tortrix moth (Lepidoptera: Tortricidae). Appl. Entomol. Zool. 15: 140-150. 
Shorey H.H. \& Gaston L.K. 1970: Sex pheromones of noctuid moths. XX. Short-range visual orientation by pheromonestimulated males of Trichoplusia ni. Ann. Entomol. Soc. Am. 63: $829-832$

Soderstrom E.L., Brandl D.G., Myerson J., Buttery R.C. \& MACKEY B.E. 1985: Sex pheromone for attracting western grapeleaf skeletonizer (Lepidoptera: Zygaenidae). J. Econ. Entomol. 78: 799-801.

Subchev M., Harizanov A., Francke W., Franke S., Plass E., Reckziegel A., Schroder F., Pickett J.A., Wadhams L.J. \& Woodcock C.M. 1998: Sex pheromone of the female vine bud moth, Theresimima ampellophaga Bayle-Barelle (Lepidoptera: Zygaenidae), comprises (2S)-butyl (7Z)-tetradecenoate. J. Chem. Ecol. 24: 1141-1151 and Erratum: J. Chem. Ecol. 25[1999]: 1203.

Subchev M., Toshova T., Tóth M., Voigt E., Mikulás J. \& FrancKe W. 2004: Catches of vine bud moth Theresimima ampellophaga (Lep., Zygaenidae: Procridinae) males in pheromone traps: effect of the purity and age of baits, design, colour and height of the traps, and daily sexual activity of males. J. Appl. Entomol. 128: 44-50.

Toshova T. \& Subchev M. 2003: Sex pheromone communication in Theresimima ampellophaga Bayle-Barelle (Lepidoptera: Zygaenidae): female calling behaviour and male electroantennographic response to synthetic pheromone compounds. Acta Zool. Bulg. 55: 43-51.
VICKERS N.J. \& BAKER T.C. 1994: Visual feedback in the control of pheromone-mediated flight of Heliothis virescens males (Lepidoptera: Noctuidae). J. Insect Behav. 7: 605-632.

VICKERS N.J. \& BAKER T.C. 1997: Chemical communication in heliothine moths. VII. Correlation between diminished responses to point-source plumes and single filaments similarly tainted with a behavioural antagonist. J. Comp. Physiol. (A) 180: 523-536.

WILLIS M.A. \& BAKER T.C. 1988: Effects of varying sex pheromone component ratios on the zigzagging flight movements of the oriental fruit moth, Grapholita molesta. J. Insect Behav. 1: $357-371$

WILLIS M.A. \& BAKER T.C. 1994: Behaviour of flying oriental fruit moth males during approach to sex pheromone sources. Physiol. Entomol. 19: 61-69.

Willuis M.A., David C.T., Murlis J. \& Cardé R.T. 1994: Effects of pheromone plume structure and visual stimuli on the pheromone-modulated upwind flight of male gypsy moths (Lymantria dispar) in a forest. J. Insect Behav. 7: 385-409.

WitzGall P. \& Priesner E. 1984: Behavioural responses of Coleophora laricella male moths to synthetic sex attractant, (Z)-5-decenol, in the field. Z. Angew. Entomol. 98: 15-33.

Zagatti P. \& Renou M. 1984: Les pheromones sexuelles des zygènes. Le comportement de Zygaena filipendulae L. (Lepidoptera, Zygaenidae). Ann. Soc. Entomol. Fr. 20: 439-454.

Received April 14, 2006; revised and accepted October 11, 2006 